\title{
A QUALITATIVE ASSESSMENT OF STUDENT ATTITUDES TO THE USE OF BODY PAINTING AS A LEARNING TOOL IN FIRST YEAR HUMAN ANATOMY: A PILOT STUDY
}

\author{
Hayley Green *1, Manisha R Dayal ${ }^{1}$. \\ ${ }^{* 1}$ School of Science and Health, Western Sydney University, NSW, Australia. \\ ABSTRACT
}

Background: The use of body painting as a method of engaging students in the learning of anatomy has been demonstrated as being beneficial to knowledge retention amongst medical students. However, the benefit of the use of body painting as an educational tool for non-medical students learning anatomy is relatively understudied.

Aims: This research aimed to assess the perceptions of first year non-medical tertiary students on the use of body painting as an engaging and useful tool for learning human anatomy. A secondary aim was to determine if students' assessment of the activity differed between those enrolled in a generalised Medical Science degree compared to those in a Clinical Health Science degree with a specific career path.

Materials and Methods: A total of two hundred first-year students divided between a Medical Science degree $(n=101)$ and the Clinical Health Sciences $(n=99)$ were surveyed using a combination of Likert scale and openended responses to determine if students thought body painting had a place in anatomy teaching.

Results: Quantitative results found no significant difference in the reported level of enjoyment experienced during body painting activities, with students finding the activity reasonably enjoyable (3.6-3.8/5), however Clinical Health Science students found the activity most useful as a learning tool ( $\left.3.9 / 5 ; p d^{\prime \prime} 0.01\right)$. Thematic inductive analysis revealed that students from both cohorts found the activity fun and interactive and that it promoted engagement and information retention. Students also recognised the benefit of the activity for visual and kinaesthetic learners. Clinical Health science students were the only cohort to report on how body painting helped linked to their future in clinical practice.

Conclusions: Student feedback supports the use of body painting as a learning tool in human anatomy in nonmedical degree programs, and contributes to the development of a stronger undergraduate anatomy teaching program.

KEY WORDS: body painting, anatomy, Health Science, undergraduate teaching, deep learning.

Address for Correspondence: Hayley Green, Western Sydney University, School of Science and Health, Locked Bag 1797, Penrith 2751 NSW Australia. Phone: +612 46203697

Fax: +612 46203025 E-Mail: H.Green@westernsydney.edu.au ORCID: 0000-0001-7765-9450

Access this Article online

Quick Response code

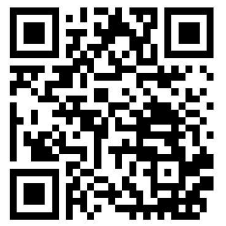

DOI: $10.16965 /$ ijar.2018.140

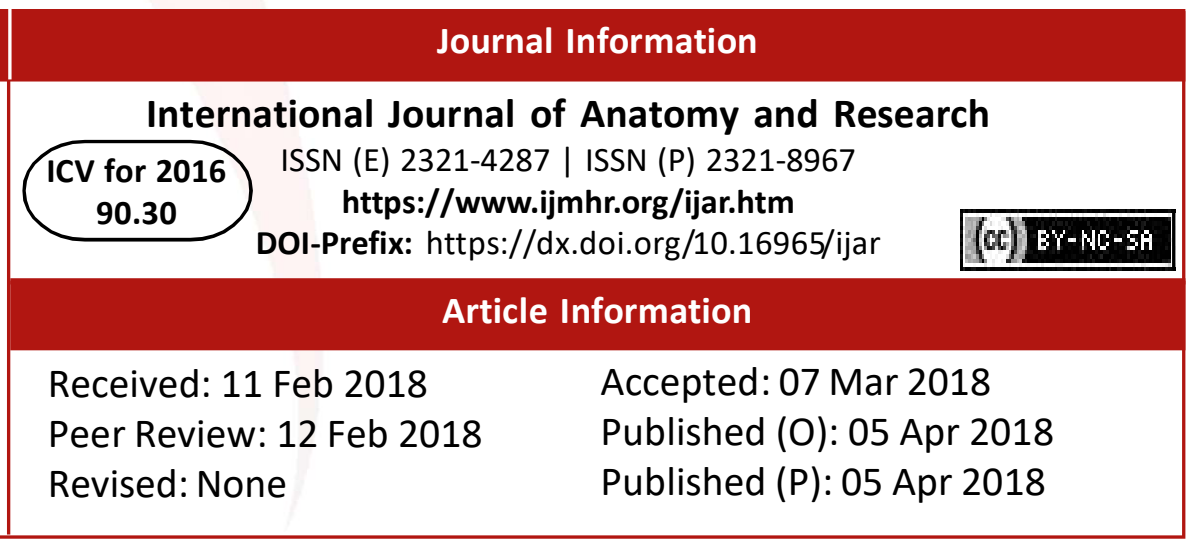

\section{INTRODUCTION}

The way in which a student learns in higher education, in general, can be categorised as either 'surface', 'deep' or 'achieving' [1, 2].

Surface learning involves rote learning and memori-sation and is typically driven by the fear of failure [3,4]. The deep approach is generally adopted when there is an interest in the subject matter, with students seeking the underlying meaning of each task and attempting to integrate each task with other activities $[5,6]$. The achieving model sees students forming study 
skills or strategies to essentially achieve high grades [5].

Research has suggested that deep learning approaches in higher education is the preferable method [2] and adoption of this approach correlates with higher grades [7] and greater retention rates [8].

First year students in particular have been found to adopt surface learning approaches at University regardless of the subject area because of their experience of learning at school, which is largely through ' passive absorption of external knowledge' [9]. Previous studies have suggested, however, that surface approaches can be a successful stepping stone to deep learning strategies later in their learning [10], particular content heavy areas of study such as languages and the sciences $[7,2]$.

Further, first year students have been found to move between the two strategies at key points in their first year, with motivation to adopt surface approaches largely assessment-driven [11] .

It is commonly accepted in higher education that the more engaged a learner, the more interested and motivated they will become and the better the learning experience they will ultimately have [12]. However, some topics are harder to engage students in than others, and negative attitudes towards topics that are perceived as 'difficult' by the students can act as a barrier to their learning and engagement [12].

The discipline of human anatomy is one particular topic that is traditionally viewed as very content heavy [13], with students typically adopting a 'surface' approach to memorise anatomical structures and lists of anatomical terms $[14,15]$. First year anatomy students in particular find learning anatomy difficult due to complex terminologies and concepts, which students perceive as 'dull' [14]. Content heavy subjects delivered over a single semester have been known to negatively affect the student learning experience [16].

Human anatomy is taught at many Universities and Colleges both in Australia and internationally and from both a basic science and clinical perspective. The principle method of teaching anatomy has historically included a series of didactic lectures and practical laboratory sessions that involve the dissection of a human cadaver, viewing of prosected cadaveric material, and commercially available anatomical models [17-19].

At Western Sydney University, the first year anatomy units generally follow a didactic mode of teaching, with students typically exposed to a single two hour lecture per week and one two hour practical class per week where students reinforce lecture material using the aforementioned prosected cadaveric material and anatomical models. Human anatomy is taught to large cohorts of first year students (e.g $>400$ ) in both the Medical Science degree program and the Clinical Health Sciences. In the Medical Science degree, students experience human anatomy in the first semester of their first year. This anatomy unit is a core unit to all major streams and a prerequisite unit to the Anatomy and Physiology major beginning in their second year of study. In the Clinical Health Sciences, which includes degree programs such as Physiotherapy, Podiatry and Sports and Exercise Science human anatomy is taught as a core unit in the first and second semesters of the first year program and is a prerequisite to second year units in each specific degree program.

A reduction in the number of cadavers available for the teaching of human anatomy has been observed worldwide $[20,21]$, as well as a reduction in face to face teaching hours [14,2224]. These factors have seen anatomy education undergo changes to develop ways to best teach human anatomy that will be of the greatest benefit to the student with limited time and resources $[14,25]$. Methods being implemented include i) peer examination, where students are required to palpate anatomical features on each other $[19,25]$, ii) body projection, where powerpoint images are projected onto student volunteers, giving students a non-obtrusive view of what is underneath the skin [19] and iii) computer programs that allow students to virtually dissect human cadavers in three dimensions [26-28]. Recently, anatomy teaching has incorporated the technique of body painting into the practicals in an attempt to create an active, positive and engaging learning experience [14, 16, 29-31]. Enhancing student engagement is considered fundamental in improving student 
retention and success $[32,33]$ and that encouraging and assisting students to engage with a topic is vital to laying the foundation for successful study in later years [34].

Body painting is fast gaining popularity as a means of teaching surface or living anatomy [14, $16,17,20,29-31,35]$. Internal structures are painted on the surface of the body (Figure 1) to give students a better understanding and appreciation of dimensions and positions of anatomical structures $[20,36]$. The activity compliments the teaching of clinical skills such as palpation, while also providing 'vivid' and memorable experiences which allow for quicker recall of anatomical information [20]. Other reported benefits to the activity include breaking down feelings of vulnerability and apprehension surrounding physical contact and nudity, which helped prepare students for their future interactions with patients $[20,30]$.

Despite the increasing popularity of body painting as a learning tool in human anatomy, it is still a relatively under-researched area [20]. Studies that have been conducted previously predominantly focus on the application of the activity in medical schools $[14,17,20,30]$, with assessment of how the activity works in nonmedical degrees such as Medical Science and Clinical Health science anatomy limited $[14,16]$. In the present study, the authors will describe how body painting was introduced for the first time into the anatomy practical teaching sessions of two first year non-medical anatomy cohorts at Western Sydney University, Australia. The first cohort consisted of first year Clinical Health Sciences where, for the most part, students have a clear pathway to a career at the conclusion of the degree. The second cohort was comprised of first year students in the Bachelor of Medical Science, a more generalised basic science degree in comparison to the Clinical Health science cohort where majors and career paths are, from experience, not typically decided late in the first year at minimum.

The aim of this study was to introduce first year students to a novel interactive learning activity that has been shown to encourage a 'deep' learning approach alongside 'traditional' learning resources to determine if the innovative method is viewed favourably as a learning resource in first year human anatomy. A secondary aim was to compare and contrast attitudes to this specific active learning technique between a clinical and non-clinical first year science cohort to determine if there are differences in attitudes between clinically oriented and non-clinical cohorts of students. Survey responses that describe student attitudes towards the body painting activity and their views on its effectiveness as a learning tool will be presented.

\section{MATERIALS AND METHODS}

Recruitment: Clinical Health Science students enrolled in the Functional Anatomy Unit in the second semester $2014(n=427)$ and Medical Science students in the Introduction to Anatomy Unit in the first semester of semester 2015 ( $n=$ 430) were invited to participate in this study. Students from the Clinical Health stream were enrolled in either first year Physiotherapy, Sport and Exercise Science, Podiatry, or second year Occupational Therapy. The Functional Anatomy Unit focuses on the musculoskeletal and surface anatomy of the trunk, head, neck and limb regions and students must complete a first semester unit on the anatomy and physiology of the musculoskeletal, nervous and endocrine systems before enrolling in the more focused Functional Anatomy. Introduction to Anatomy provides students with an overview of all body system, including the musculoskeletal, nervous and all visceral systems. Students enrolled in this unit typically have no prior exposure to human anatomy or physiology at a higher education level at the time of enrolling.

An invitation to participate in the anonymous survey was sent through the online University Learning Management System and via student email. Information sheets were provided with the survey, outlining the purpose of the project, the anonymity of the participants and how the results would be disseminated. Ethical permission to conduct this study was approved by the Human Research Ethics Committee at Western Sydney University, Australia (H10863).

Practical class format: Students from both cohorts attended a single weekly two-hour practical for their specific human anatomy unit that 
was designed to reinforce the information delivered in the weekly lecture. The practicals were designed to be self-directed under the supervision of a staff member. Students were provided with a checklist of the important anatomical and surface structures for each topic. Checklists provide a standardised resource for students that can assist with maintaining concentration during practical classes to promote better understanding of fundamental anatomical structures [22].

Students were free to move around the anatomy laboratory and choose the resource(s) that best suited their learning style. Learning resources provided included traditional cadaveric specimens, anatomical models and medical imaging ( $x$-rays) and for the first time in these two units, a body painting station was included. Practicals were followed up with formative practical review questions consisting of short answer and labelling questions.

Body painting activities were suggested for all 12 practicals in the functional anatomy unit for Clinical Health students (trunk head and neck, upper limb, lower limb and neurovascular structures), while the Medical Science students had the activity included in 5 practicals (bones, joints, muscles, cardiovascular system and gastrointestinal system). Non-toxic body paints, paintbrushes of varying size and markers for landmarking surface features were provided in class. Step by step instructions and diagrams for body painting activities were also provided to each student (Figure 2). Emphasis for the body painting was placed on superficial structures that could be easily palpated and/or had a relationship with visible and palpable surface landmarks (e.g. tibial tuberosity, proximal tibia, contracted quadriceps femoris muscle group). No specific time limit was allocated to the body painting activity in class, with the students themselves deciding the amount of time they would devote within the 2 hours of practical class time to engage with the activity. Body painting was also not used in any formal assessment items. Participation in the body painting activity was thus encouraged, but not compulsory. All students who are depicted in the figures provided written permission for the images to be published.
Evaluation process: A questionnaire collected data on the body painting and other aspects of their learning experience in the anatomy practicals (Table 1). Students were asked to indicate if they had participated in the body painting activity, how enjoyable they found the activity, their perceived usefulness of the activity as a learning tool, and how likely they were to recommend the activity as a learning tool to their peers and why. This questionnaire was anonymous, with no demographic data or other identifying information recorded to encourage participation. The questionnaire was distributed at the conclusion of the teaching semester, with the survey remaining open until the end of the formal examination period. Students were sent weekly requests for four weeks via email to participate in the online survey. Responses were a combination of a five-point Likert scale, where responses ranged from 'strongly disagree' to 'strongly agree'. Open response questions were also utilised to give students more opportunity to express their opinions.

Qualitative Analysis: Open-ended questions were analysed by thematic (inductive) analysis, informed by grounded theory approach [37]. This is a qualitative method used for identifying and analysing themes within data [38]. A single author (HG) firstly read all open-ended student responses without taking notes. During subsequent reads, the same author independently coded the written responses, resulting in 10 preliminary topics. These topics were further grouped into 3 themes that were common to both cohorts of students. Thematic analysis was performed manually by the author (HG).

Quantitative Analysis: Quantitative data from the 5-point likert scale questions were coded numerically into a score of 1 (strongly disagree) to 5 (strongly agree). These variables then underwent independent sample t-tests to assess bivariate associations between the self-reported satisfaction variable and the students' degree program (Medical Science or Clinical Health Science). All statistics were performed using SPSS release 22 for Windows.

\section{RESULTS}

Survey return: Of the $n=427$ Clinical Health science surveys and $n=430$ Medical Science 
surveys distributed, approximately 100 surveys were returned for Clinical Health and Medical Science, respectively (23\%). Of the returned surveys from Clinical Health science students, $56 \%$ stated they had used the body painting activity at least once, while approximately $60 \%$ of Medical Science students participated at least once. Useable responses to the satisfaction variables decreased to between 74-77 responses in the Clinical Health science cohort and 81-84 responses in Medical Science (Table 1).

\section{Quantitative analysis of self-reported satisfac-} tion variables:

Results show no significant difference in enjoyment levels between the first year Clinical Health science and Medical Science students, with the mean ranging between 3.6-3.8/5 (Table 1 ). Where the two cohorts differ is when rating the usefulness of the body painting as a learning tool and whether students would recommend the activity to others, with Clinical Health science students rating these variables significantly higher than the Medical Science students ( $p$ $<0.01$, respectively).

\section{Qualitative analysis of self-reported satisfac- tion variables:}

Students were asked to expand on their rating to the question "I would recommend this activity to others" with the open-ended question "Why would/wouldn't you recommend this activity to others?". To support why students would recommend the activity, three main thematic areas common to both Clinical Health and Medical Science students emerged from the qualitative data: 1) Encourages understanding and enhances retention, 2) A fun and interactive way to learn and 3) Learning style. An additional thematic area unique the Clinical Health science students was 4) Linked theory to real-life applications. Discussion of these themes and exemplary comments are below.

\section{Encourages understanding and enhances retention:}

Students from both cohorts who would recommend this activity made reference to the body painting activity helping them 'remember' and 'understand' anatomicalcontent, particularly surface markings of muscles and palpable bony landmarks:
"Gave me a better understanding of exactly where organs are in the body and helped me locate them in an exam situation."

Really helped solidify my understanding when looking at the structures of the forearm."

"You gain a deeper understanding after you have had to apply knowledge to a real painting."

However, no specific details as to what aspect of the activity helped with information retention, such as the colour or the act of palpating structures, was described by either cohort.

A fun and interactive way to learn: The body painting activity appealed to students due to the 'fun' and 'hands-on' nature of the activity and was often linked to terms such as 'enjoyment', 'creative' and 'easier learning'. Student comments were either focussed on how fun the activity was itself, or how the activity created a 'fun' learning environment:

"Forced me to form holistic active concrete learning which will stay with me throughout my university career. I wish all anatomy units and units in general promoted learning activities like this which encourage active learning."

"It was engaging and fun which made learning the subject more enjoyable and easier."

"Learning in a fun environment helps you remember."

"It provides a hands-on experience for learning which textbooks do not provide."

Learning style: Interestingly, this theme emerged amongst students from both cohorts who did not participate or enjoy the body painting themselves but would recommend body painting to their peers if they believed that student was suited to kinaesthetic and/or visual learning methods. Students appreciated having both innovative and traditional learning activities available to all students in the practicals options and were able to identify their own personal learning preference because of the exposure to the different options:

"People have different learning styles so it is good to have this option in class."

"Students have a way to actively engage if they do not prefer traditional methods."

"For visual and interactive learners I think it would be a helpful learning tool." 
"Whilst the learning technique was not overly effective for me, I can see why it would be a great way to learn."

"If it helps others then great!"

"Even though I did not use body painting as a tool I can see the benefits."

Linked theory to real-life applications: A theme that emerged in the Clinical Health cohort, but was not seen amongst the Medical Science students, was that which related to being able to see the relevance and importance of surface anatomy and the act of palpation to their future as health professionals:

"(Body painting is) Effective in locating anatomical landmarks, which is crucial and is required in a professional setting."

"You associate surface anatomy with actual properties beneath the skin which will obviously help in the future when dealing with real patients."

"It helps orientate yourself in a real life setting and we will need to be doing this later on as health professionals."

Despite a majority of students surveyed indicating that they would recommend the body painting for the reasons described above (table 1), there were a number of students in both cohorts who stated that they would not recommend body painting to others. Thematic areas emerging from the qualitative analysis were 1) time constraints, 2) messy and uncomfortable and 3) poor artistic ability. Exemplary comments on each theme are below:

Time constraints: Students reported that the body painting activities were time consuming and they did not consider it an activity that would be useful during the time limits of the practical session. Instead, many of the students chose to focus more on the cadavers and models in class as they felt this would be a better use of their time, particularly as there was a staff member on hand to assist and because these resources were examinable content:

"A waste of valuable time spent in the lab"

"Even though the pracs are two hours, we never really had time"

"Not enough time to look at cadavers, models AND bodypaint. Spending a lot of time with cadavers was the main focus as our assessment focussed on it"

"Personally I spend my time identifying structures on cadavers and models with my tutor to clarify structures"

Messy and uncomfortable: Students stated the messiness associated with the paint itself and the time taken to remove the paint as a factor in their decision not to participate in body painting:

"Did not want the inconvenience of having to wash after body painting activities."

"Paint is messy and would be a hassle to clean up."

A small number of students also reported feeling uncomfortable with the thought of having to apply paint to themselves in front of their peers, or to their peers directly, particularly if they were not 'friends' with their classmates. While not directly measured, this theme emerged more strongly in the Medical Science cohort:

“I didn't feel comfortable and I didn't have any friends that I was close enough in class for me to paint on them and vice versa."

"Did not feel comfortable"

"I think applying paint to your body or someone else's can be uncomfortable."

Fig. 1: Example of body painting of the knee joint (a) and anterior thigh muscles (b) produced by first year students in this study.

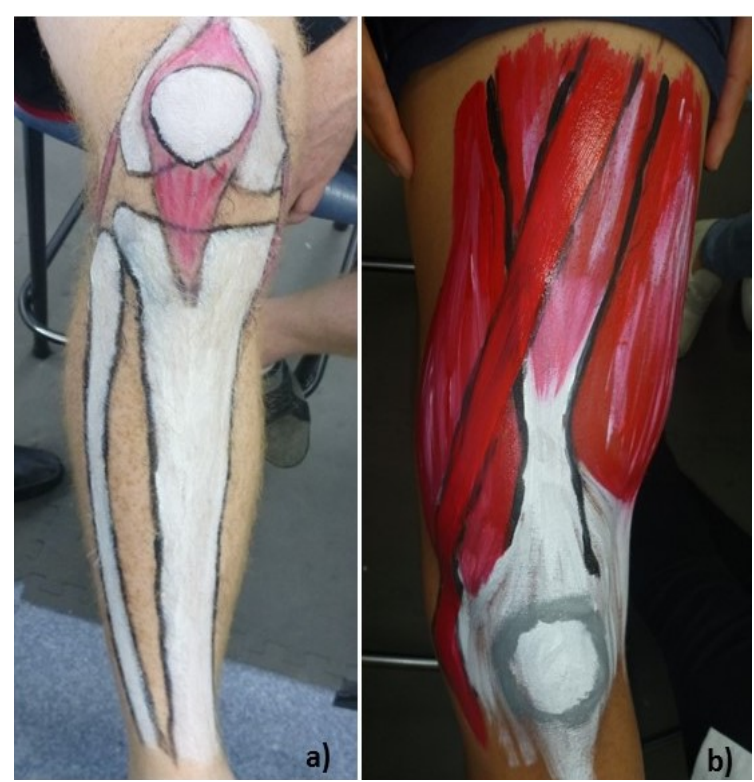

Poor artistic ability: A common theme found across both cohorts of students was the fear of poor artistic ability. Students predict a link with 
'bad' painting and learning the anatomical content incorrectly, opting for more traditional resources (cadavers and anatomical models) as in their opinion, there is less chance of error in identifying structures this way:

"I'm not very good at art so I probably would have just confused myself."
"I'm not very creative so attempting to draw the structures wasn't that helpful as I couldn't get it to look right."

"I am bad at painting and drawing and I don't love art in general."

"If they are bad at art like me it just makes it harder."

Fig. 2: An example of the step by step body painting instructions provided to students during practical classes.

\section{BODY PAINTING ACTIVITY 1: The Knee joint}

\section{You will need to come prepared to expose the knee region like wearing a pair of shorts. It is best to work in groups of two. One person will be the professional while the other person is the patient.}

Step 1: $\quad$ While the patient is sitting down with their knee flexed, palpate the patella. Using the texta provided, draw the outline around the patella and then paint it white (use the images provided at the station to help with the shape).

Step 2: $\quad$ Now palpate the tibial tuberosity (distal to the apex of the patella) and draw the outline with the texta.

Step 3: $\quad$ Ask the patient to flex and extend the knee while you palpate the patellar ligament. You should feel it directly between the patella and the tibial tuberosity. On the medial and lateral margins of the ligament you will feel a space. This will enable you to draw the outline of the ligament between the two bony structures above. Paint it yellow.

Step 4: $\quad$ Next palpate the epicondyles of the femur. Remember that these should be found just above each of the condyles on the lateral sides of the femur. Mark the outline with the texta and paint them white.

Step 5: $\quad$ Finally palpate the proximal tibia on either side of your patellar ligament. Remember that these are the condyles of the tibia. Mark the outline with the texta and paint it white.

Step 6: Using yellow paint, add in the collateral ligaments of the knee, paying close attention to the differences in the anatomy between the two ligaments. Use your anatomy notes to revise the attachments of each of the collateral ligaments.

Suggested further activities: Add in the distal end of the quadriceps femoris muscles and the quadriceps tendon. Pay particular attention to the feather-like pattern of the rectus femoris and the oblique fibres of the vastus muscles.

Table 1: Comparison of self-rated engagement scores between students enrolled in the 2014 Clinical Health Sciences and students enrolled in the 2014 Medical Science program. Engagement variables scored between 1 (strongly disagree) and 5 (strongly agree).

\begin{tabular}{|l|c|c|c|}
\hline & $\begin{array}{c}\text { Clinical Health } \\
\text { Sciences }\end{array}$ & $\begin{array}{c}\text { Medical } \\
\text { Sciences }\end{array}$ & $p$-value \\
\hline Returned surveys & $99 / 427$ & $101 / 430$ & - \\
\hline I participated in the body painting activity at least once (\%) & $56 \%$ & $59 \%$ & - \\
\hline I found this activity enjoyable (mean \pm S.D) & $3.8(0.8)$ & $3.6(0.8)$ & $0.143^{\text {a }}$ \\
\hline I found this activity to be a useful learning tool (mean \pm S.D) & $3.9(0.8)$ & $3.5(0.9)$ & $0.003^{\mathrm{a}}$ \\
\hline I would recommend this activity to other students (mean \pm S.D) & $4.0(0.7)$ & $3.6(0.9)$ & $0.004^{\mathrm{a}}$ \\
\hline
\end{tabular}




\section{DISCUSSION}

The aim of this study was to survey first year students in content heavy non-medical anatomy units as to their perception of the innovative, non-traditional learning activity of body painting as an engaging learning tool. A second aim was to compare and contrast student opinions of students enrolled in applied the applied Clinical Health Sciences versus students in a more generalised Medical Science program.

As the quantitative results showed, there was no difference in the reported enjoyment level between the two cohorts of students. The qualitative analysis demonstrated those students who participated in the body painting activity found it 'fun' and 'engaging' and voiced how it appealed to and enhanced their preferred learning style. It was interesting, but unsurprising, that the Clinical Health science students found the activity 'useful' in comparison to the Medical Science students, as evidenced by the comments and the quantitative analysis. This can be explained by the students in this cohort finding the activity relevant to their future clinical careers. The link between the body painting and professional knowledge has been made previously $[20,30]$, with studies showing that students who see the link between teaching and professional practice are more likely to sustain their interest in the subject matter [39]. The Medical Science degree at Western Sydney University provides students with broad based knowledge of the Medical Sciences such as anatomy, physiology, microbiology and chemistry. As this cohort are introduced to anatomy in the first semester of their first year of such a broad degree, the relevance of anatomy to the rest of their degree may not be immediately clear. This may act as a barrier to their learning of the subject, particular if their career path may also yet be undecided at this early stage of their degree, and may explain why this theme did not emerge from their comments. Nonetheless, the lack of recognising the relevance of the body painting did not necessarily detract from the enjoyment of the activity in this cohort.

An interesting outcome of the study was the finding that students who chose not to participate or engage with the body painting as a learn- -ing tool were still able to appreciate that the activity would be beneficial and appealing to a different kind of learner, and in doing so, these students were able to recognise their own learning style preference, or at least identify how they did not want to learn the content. These other preferred learning styles, as demonstrated by the qualitative data, predominantly focussed around interacting with the more traditional resources such as the cadaveric material. Justification by students for using these resources instead of the more interactive approach of the painting included time constraints in the practical classes, the anticipation of mess and at times, feelings of discomfort around painting themselves in front of their peers or painting their peers when there was no pre-established familiarity. Mention of utilising assessable content only during class was also made, which is not surprising in a first year, first semester group of students, whom studies have suggested are largely assessment-driven in their learning approaches [40]. The issues of time and a desire for students to want to concentrate on assessable content only is crucial information to enable the authors to design more appropriate practical classes in the future. This may involve dedicating one or more two hour practical classes specifically to surface anatomy/body painting sessions, and the authors would suggest introducing the activity later in the degree program (ie, from second year onwards) when students potentially have a clearer career path and therefore better see the usefulness of the activity. As students progress further into their degree, feelings of being uncomfortable or not having confidence to carry out the painting themselves may also diminish with time, potentially encouraging more students to participate. Incorporating the body painting or a surface anatomy assessment would also be recommended, particularly if the activity is used early in a degree program where assessment is the main focus of the students.

The use of body painting as a learning tool is increasing in popularity, particularly in medical schools both internationally $[17,20]$ and within Australia [30]. More recently, innovation in human anatomy teaching using techniques such as body painting, is being seen in non-medical 
degree programs $[14,21]$. There is a general consensus that the activity promotes 'active' and 'deep' approaches to learning [14, 20] which is beneficial to the student as it promotes information retention and indicates that a student is engaging meaningfully with the content and is able to apply the knowledge appropriately [7]. It is advised, however, that body painting not be over-used, and that a targeted approach may be more impactful in terms of anatomical knowledge [20] and perhaps student engagement and participation in the activity. Researchers also agree that this technique should not replace traditional resources for learning anatomy such as cadaveric specimens and anatomical models, but should be used as a complementary activity, with body painting providing opportunity to consolidate, build on and apply knowledge gained during didactic teaching sessions [20, 41]. The suggestion of a multimodal approach to learning is particularly important in the context of student learning in the first year of learning in a tertiary environment. There is a body of research that suggests that at a first year level, when students are transitioning from a 'passive absorption' learning method at high school, a combination of deep and surface learning approaches should be encouraged, as it is unrealistic to expect recent school leavers to adopt deep approaches to learning consistently [40].

This study was limited by the relatively low response rates across both cohorts of students. Low response rates could be attributed to the timing of the distribution of the questionnaires immediately before and during the formal examination period, and/or the online method of distribution. The study was also potentially limited by the questionnaire not capturing the demographic information of the participants, such as age, gender, specific degree program for the Clinical Health science cohort and whether the Medical Science students planned to undertake a Medical degree in the future. This information was not collected, as it was thought that the more anonymous the survey, the more students would participate. Future studies would therefore seek to collect demographic data from participants. The present study also compared two very different cohorts, one of which is targeted in terms of career paths in which the relevance and importance of human anatomy to that career is clear, and the other being more general in terms of career progression where the importance of this subject to a students' overall progression is not as obvious in comparison. This is likely to have impacted the degree to which students found the activity useful in their learning of the anatomical content between the two cohorts. This research would benefit from access to the assessment marks for each participant to track performance against the reported 'fun' and 'engaging' activities, and perhaps also conduct a longitudinal study that follows student performance in the students from first year anatomy units through to final year units to assess the impact of the learning tools we implement over a longer period of time. A correlation between enjoyment and increased academic performance could act as a confirmation that the activities are both engaging and a useful learning resource and is something that needs to be explored in the future.

\section{CONCLUSION}

While the literature predominantly focuses on the benefits of innovative teaching methods such as body painting in medical education, the results of the present study therefore suggest that there is a place for body painting in the anatomy curriculum for non-medical students, as it provides alternative learning tools for students who have already identified themselves as visual and tactile learners and enhances their learning experience. The use of body painting and other 'deep learning' methods of learning human anatomy outside of a medical curriculum is relatively understudied, particularly in Australia, and the present research contributes to bridging that knowledge gap.

This research suggests that the activity is more beneficial to students when the relevance to their future professions is made clear. This finding will allow for future curriculum changes to the Medical Science anatomy units at Western Sydney University in particular where the relevance and importance of the activity could be made more obvious, or perhaps to introduce the activity in anatomy units that occur later in the 
degree program. More broadly, the study also demonstrates that there is much diversity amongst first year students in their learning styles (passive versus active) and their preference for traditional (cadaveric) versus nontraditional (body painting) learning tools. The study therefore supports previous research that has identified that a multimodal approach, with a combination of interactive and non-traditional methods such as body painting used in conjunction with the more traditional anatomical resources of cadavers and models, is the most appropriate teaching approach at a first year level to maximise engagement.

\section{ACKNOWLEDGEMENTS}

The authors wish to thank Associate Professor Peter Shortland of Western Sydney University, whose comments were invaluable in the preparation of this manuscript, and Dr Kate McBride for her advice and assistance with the qualitative analysis.

\section{Conflicts of Interests: None}

\section{REFERENCES}

[1]. Biggs J. Individual differences in study processes and the quality of learning outcomes. High Educ 1979; 8: 381-394.

[2]. Entwistle NJ, Peterson ER. Conceptions of learning and knowledge in higher education: Relationships with study behaviour and influences of learning environments. Int J Educ Res 2004; 41: 407-428.

[3]. Entwistle NJ, Smith C. Personal understanding and target understanding: Mapping influences on the outcomes of learning. Br J Educ Psychol 2002; 72 321-342.

[4]. Newble DI, Entwistle NJ. Learning styles and approaches: implications for medical education. Med Educ 1986; 20: 162-175.

[5]. Biggs J. Approaches to the enhancement of tertiary teaching. High Educ Res Dev 1989; 8: 7-25.

[6]. Trigwell K, Prosser M. Improving the quality of student learning: the influence of learning context and student approaches to learning on learning outcomes. High Educ 1991; 22: 251-266.

[7]. Biggs J, Tang C. Teaching for quality learning at university: what the student does. Philadelphia: Society for Research into Higher Education; 2007.

[8]. Ramsden P. Learning to teach in higher education. Routledge; 2003

[9]. Wingate U. A framework for transition: supporting 'learning to learn' in higher education. High Educ Q 2007; 61:391-405.

[10]. Ryan J, Louie K. False dichotomy? 'Western' and 'Confucian' concepts of scholarship and learning. Educ Phil Theory 2007; 39: 404-417.
[11]. Penn Edwards S, Donnison S. Engaging with higher education academic support: A first year student teacher transition model. Eur J Educ Stud 2011; 46: 566-580.

[12]. Allen PJ, Baughman FD. Active learning in research methods classes is associated with higher knowledge and confidence, though not evaluations or satisfaction. Front Psychol 2016; 7: 279.

[13]. Mitchell BS, McCrorie P, Sedgwick P. Student attitudes towards anatomy teaching and learning in a multiprofessional context. Med Educ 2004; 38: 737 748.

[14]. Diaz CM, Woolley T. Engaging multidisciplinary first year students to learn anatomy via stimulating teaching and active, experiential learning approaches. Med Sci Educ 2015; 25: 367-376.

[15]. Miller SA, Perrotti W, Silverthorn DU, Dalley AF, Rarey KE. From college to clinic: Reasoning over memorization is key for understanding anatomy. Anat Rec 2002; 269: 69-80.

[16]. Nicholson LL, Reed D, Chan C. An interactive, multimodal Anatomy workshop improves academic performance in the health sciences: a cohort study. BMC Med Educ 2016; 16: 7.

[17]. Finn GM, White PM, Abdelbagi I. The impact of color and role on retention of knowledge: $A$ body-painting study within undergraduate medicine. Anat Sci Educ 2011; 4: 311-317.

[18]. Kerby J, Shukur Zn, Shalhoub J. The relationships between learning outcomes and methods of teaching anatomy as perceived by medical students. Clin Anat 2011; 24: 489-497.

[19]. McLachlan JC, Regan De Bere S. How we teach anatomy without cadavers. Clin Teach 2004; 1: 4952.

[20]. Finn GM, McLachlan JC. A qualitative study of student responses to body-painting. Anat Sci Educ 2010; 3: 33-38.

[21]. Nanjundaiah K, Chowdapurkar S. Body-painting: A tool which can be used to teach surface anatomy. J Clin Diagn Res 2012; 6: 1405-1408.

[22]. Engebretson Hofer R, Nikolaus OB, Pawlina W. Using checklists in gross anatomy laboratory improves learning outcomes and dissection quality. Anat Sci Educ 2011; 4: 249-255.

[23]. Heylings DJA. Anatomy 1999-2000: The curriculum, who teaches it and how? Med Educ 2002; 36: 702710 .

[24]. Turney BW. Anatomy in a modern medical curriculum. Ann Royal Coll Surg Engl 2007; 89: 104-107.

[25]. McLachlan JC, Bligh J, Bradley P, Searle J. Teaching anatomy without cadavers. Med Educ 2004; 38: 418424.

[26]. Hallgren RC, Parkhurst PE, Monson CL, Crewe NM. An interactive, web-based tool for learning anatomic landmarks. Acad Med 2002; 77: 263-265.

[27]. Pereira JA, Pleguezuelos E, Merí A, Molina-Ros A, Molina-Tomás $C$, Masdeu C. Effectiveness of using blended learning strategies for teaching and learning human anatomy. Med Educ 2007; 41: 189-195. 
[28]. Petersson H, Sinkvist D, Wang C, Smedby Ö. Webbased interactive 3D visualization as a tool for improved anatomy learning. Anat Sci Educ 2009; 2: 61-68.

[29]. Cody J. Painting anatomy on anatomy. J Biocommun 1995; 22: 14-17.

[30]. McMenamin PG. Body painting as a tool in clinical anatomy teaching. Anat Sci Educ 2008; 1: 139-144.

[31]. Op Den Akker JW, Bohnen A, Oudgeest WJ, Hillen B. Giving color to a new curriculum: Bodypaint as a tool in medical education. Clin Anat 2002; 15: 356362.

[32]. Chen HL, Lattuca, LR, Hamilton ER. Conceptualizing engagement: Contributions of faculty to student engagement in engineering. J Eng Educ 2008; 97: 339-353.

[33]. Horstmanshof L, Zimitat C. Future time orientation predicts academic engagement among first year university students. Br J Educ Psychol 2007; 77: 703718.

[34]. Krause KL, Coates H. Students' engagement in first year university. Assess Eval High Educ 2008; 33: 493-505.
[35]. Finn GM. Twelve tips for running a successful body painting teaching session. Med Teach 2010; 32: 887890.

[36]. Bruner JS. The act of discovery. Harv Edu Rev 1961; 31: 21-32.

[37]. Patton MQ. Designing qualitative studies. Qual Res Eval Meth 2002; 3: 230-246.

[38]. Braun V, Clarke V. Using thematic analysis in psychology. Qual Res Psychol 2006; 3: 77-101.

[39]. Jason $\mathrm{H}$. Becoming a truly helpful teacher: considerably more challenging, and potentially more fun, than merely doing business as usual. Adv Physiol Educ 2007; 31: 312-317.

[40]. Donnison S, Penn-Edwards S.Focusing on first year assessment: Surface or deep approaches to learning? Int J FYHE 2012; 3: 9.

[41]. Minhas PS, Ghosh A, Swanzy L. The effects of passive and active learning on student preference and performance in an undergraduate basic science course. Anat Sci Educ 2012; 5: 200-207.

How to cite this article:

Hayley Green, Manisha R Dayal. A QUALITATIVE ASSESSMENT OF STUDENT ATTITUDES TO THE USE OF BODY PAINTING AS A LEARNING TOOL IN FIRST YEAR HUMAN ANATOMY: A PILOT STUDY. Int J Anat Res 2018;6(2.1):5134-5144. DOI: 10.16965/ ijar.2018.140 